DE DE GRUYTER

OPEN

PESD, VOL. 10, no. 1, 2016

\title{
ECOLOGICAL-GEOCHEMICAL ANALYSIS AND EVALUATION OF RURAL GEOSYSTEMS MOUNTAIN AREAS OF NORTHERN BUKOVINA (UKRAINE)
}

\author{
Tanasiuk M.V. ${ }^{1}$
}

Key words: rural geosystems, anthropogenic contamination, ecologicalgeochemical composition, ecological-geochemical situation, ecological estimation.

\begin{abstract}
The study of general ecological peculiarities of rural geosystems should be conducted on the basis of analysis and evaluation of geochemical showings. Among anthropogenic factors influencing the formation of ecological-geochemical peculiarities of rural geosystems considerable negative influence have unpractical nature management and the economic activity human being. That's why the study of ecological-geochemical condition of rural geosystems all enables us to estimate them and to determine the change dynamics.

On the basis of the conducted researches geosystems in the mountain areas of Northern Bukovina, the concentration coefficients are calculated, total showings of contamination, there being determined the showings of contamination intensivity of the natural component and the integral indicator of the ecological danger, there being given a general evaluation of the ecologicalgeochemical situation of the rural geosystems of the investigated area.
\end{abstract}

\section{Introduction.}

Landscape contamination due to the active influence of human activities leads to their transformation, i.e. change. Ecological problems solving, connected with anthropogenic geochemical influence on the environment is one of the main tasks of the majority of nature sciences. Evaluation of the area ecological condition requires the application of the ecological-geochemical

${ }^{1}$ Chernivtsy National University named after Yuriy Fedkovych, Chernivtsi, Ukraine; tanasiukmv@gmail.com 
methods of research particularly. As the most urgent task of the modern society is the improvement of the ecological conditions of the environment.

One of the main pointers of the ecological quality of the landscape complexes are the geochemical properties. Also the important moment while analyzing the ecological condition of the rural geosystems of the investigated area, which influence all the spheres of the human activity as well as nature systems functioning.

Rural geosystems are one of the most active varieties of the anthropogenic landscapes, their properties change continuously, and these changes depend on the anthropogenic loading and contamination territory.

Rural geosystems within mountain areas of Northern Bukovina have been chosen as an object of the research, as a subject-ecological-geochemical peculiarities of an area. The purpose of the study is improvement of theoreticalmethodological principles, means and methods of investigation of anthropogenic, particularly rural geosystems.

\section{Task setting.}

The study of the general ecological peculiarities of rural geosystems condition is impossible to carry out without analysis and evaluation of the geochemical showings of landscape components (soils, underground and surface waters, biomass etc).

The research of the ecological-geochemical peculiarities of the rural geosystems allows to estimate the current ecological condition of the natural components, determine the dynamics of their changes and to outline the ways for further rational usage.

The analysis of the previous researches.

The basic theoretical and methodical ground for study and research of anthropogenic and, in particular, rural geosystems comprise scientific works of domestic owe and foreign scientists such as F.M.Milkov, A.G.Isachenko, P.G.Shyshchenko, V.O.Nikolaev, L.I.Voropai, V.M.Gutsuliak, G.I.Shwebs, V.M.Pashchenko, M.D.Grodzynskiiiy, I.P.Kovalchuk, G.I.Denysyk etc.

Ecological-geochemical investigation of anthropogenic landscapes was carried out by M.A.Glazovska, Yu.E.Saet, I.A.Avessalomova, L.M.Shevchenko, V.M.Gutsuliak, L.L.Malysheva, I.M.Voloshyn.

\section{Summary of the main research results.}

Natural complexes of mountain areas of Northern Bukovina present the locations of mountain ranges and intermontane valleys. With all the diversity of the structure of mountain ranges and intermountain valleys they have certain common characteristics, typical for the Carpathian mountain country:

a) the prevalence in the lithological composition of the rocks, the so-called flysch sediments, represented by the thick layer of rhythmically-bedded sands, 
clays, sandstones and shales. Only in the extreme South of Northern Bukovina, in Chyvchyny mountain ranges are composed of metamorphic rocks (schist, gneiss, quartzite, etc) and sedimentary rocks of the Permo-Carboniferous (limestones, marbles, sandstones, conglomerates, etc);

b) a peculiar form of the folding, among which predominate moved in a southeasterly direction anticlinal folds, compressed and slipped over each other, sometimes for several kilometers. As a result of this folding, a whole series of nearly parallel ridges with asymmetrical slopes: North-West flatter and NorthEast steeper;

c) the presence of altitudinal differentiation of climatic conditions, which are generally characterized by high humidity (annual precipitation of $900-1200$ $\mathrm{mm}$ ) and moderately cold temperatures (July $17-12^{\circ} \mathrm{C}$, January $-6,0-10^{\circ} \mathrm{C}$ ) with a noticeable differences in the climate of mountain valleys and peaks of the ridges;

d) continuous distribution of forest cover in the past mainly mixed beechfir forests; only above 1200 - 1300 on the slopes of the ridges were dominated by coniferous forests, and meadows, that is, the Carpathian subalpine meadows.

Many rivers, streams, creeks divide mountain ranges on a more or less large segments whose slopes are complicated by landslides, sometimes in small steps, due to the alternation of soft shales and hard sandstones; to this we must add to the unequal exposure of the slopes, which in many ways are heated and lighted by the sun, the difference in rainfall, strength, speed winds at different slopes; all this creates in the Carpathians extraordinary diversity of naturalterritorial complexes.

The group of lithomorphological components belongs to the natural factors of formation of geochemical and ecological landscapes peculiarities. This group makes for general geochemical characteristics of basic and parent rocks, soils (lithogenic basis). Lithologic differences of rocks are connected with abilities to accumulate contaminating substances and landscape sell purification. The overall orografical plan of the investigated area is rather complicated. Altitude discrepancies, different angles of surface bias create different ecologicalgeochemical peculiarities on a small area.

Great importance in the area ecological situation forming is played by surface and underground waters, their hydrological and hydrochemical peculiarities. For instance, alkali acid and oxidation renewing conditions of water promote the change of migration ability of different substances. A considerable differentiation of water content leads to dynamic deviations in the showings of macroelements contents in water and re-distribution of microelements. 
Anthropogenic pressure of landscapes is reflected in accumulation of chemical elements in soils, plants, underground and surface waters and in the air of investigate territory. This happens both as a result of biological elementseizing and mechanical absorption of pollutants.

Anthropogenic contamination leads to landscape complexes changes and changes in landscape components geochemical peculiarities. It's possible to estimate these changes in quantity or to determine ecological condition of this or that landscape component by analysing geochemical coefficients. Various authors offered different methodical approaches to ecological condition estimation through coefficients but they all depend on the completeness of the analytical materials, which characterizes the degree of geochemical awareness of some area. The more analyses of soils, waters, air, vegetation we have, the more precisely we can evaluate the landscape ecological condition. Among showings of such estimation we can highlight clarks of concentration, coefficients of concentration, total showings of contamination ets.

In each landscape component one can find a great amound of different chemical elements a which are not harmful for a human up to certain concentrations. The average contents of a chemical elements in the earths crust (lithosphere) is called a clark. Bat in each region depending on geological structure, soils types, geographical zoning and other factors, there will be their own, characteristic only of this region, average contents of this or that element. This average contents is called a regional background. It may be more or less than a clark.

So, only the contents of chemical substances which exceed a clark and a background contents are abnormal, i.e. harmful for smooth development and functioning of an ecosystem. If the contents of this or that element exceeds limiting allowable concentrations (LAC) then this element is toxic, i.e. harmful for a human organizm.

Abnormal element contents is determined by a formula:

$$
\mathrm{Kc}=\mathrm{Ci} / \mathrm{Cf}
$$

where $\mathrm{Ci}$ - element contents in the investigated component of are landscape; $\mathrm{Cf}$ - its natural background.

On the basis carry out Kc the calculation of the saturation index of soil chemical elements, as an arithmetic average of the concentration coefficients of all the studied metals (Dmitruk,2006).

The total showings of contamination of the natural component $(\mathrm{Zc})$ are equal to the sum of the coefficients of concentration of chemicals:

$$
\mathrm{Zc}=\sum \mathrm{Kc}-(\mathrm{n}-1) \text {, }
$$

where $\mathrm{Kc}-$ coefficient of concentration element

$\mathrm{n}$ - the total number of chemical elements taken into account 
The number of aggregated elements depends on their ecological importance, from the analysis results, etc. Coefficient of concentration indicates the degree of pollution of the natural component of a specific element, and $\mathrm{Zc}$ total showings of contamination of this component.

To assess the degree of risk of pollution to the health of the population used the hazard coefficient of the element $(\mathrm{Kd})$, defined as the ratio between the content of the substances in the component to LAC:

$$
\mathrm{Kd}=\mathrm{Ci} / \mathrm{LAC} \text {, }
$$

where $\mathrm{Ci}$ - element contents in the investigated component of are landscape; LAC - limiting allowable concentration element (Gutsuliak,1994).

The coefficient of radial differentiation shows the deviation of the content of metals from the average value, that is, the nature of migration-accumulation whether it is soil, sediment. The radial coefficient of differentiation is determined by the following algorithm: the content of chemical elements in each horizon divided by the average for the entire section.

The migration index for a specific genetic horizon is calculated as the arithmetic mean of the coefficients of radial differentiation of genetic horizons of all the studied elements.

Calculations of these quantitative showings enable us to make an overall estimation of the ecological-geochemical condition of landscape components, to determine the degree of ecological changes of the environment in connection with contamination, which are carried out on the 5 - point system and according to the following criteria:

1 - favourable (contamination is absent);

2 - relatively favourable (contamination is allowable, substance contents exceeds a background one, but not more than LAC in all landscape components);

3 - relatively unfavourable (contamination is relatively dangerous, contents of chemical substances exceeds LAC in soils);

4 - unfavourable (contamination is dangerous, excess of LAC in soils and air);

5 - very unfavourable (contamination is very dangerous, substance contents exceeds LAC in all environments - soils, air, water, biota).

To estimate an ecological condition of an area one should condsider such important things as the indicator of contamination intensivity of a natural component $(\mathrm{Pj})$ and the integral indicator of ecological safety (In) of a landscape in relative units (Gutsuliak,2002).

The calculation formula is

$$
P j=\sum_{i=l}^{n} M i \cdot K c i, I n=\sum_{i=l}^{m} P j \cdot T j \text {, where }
$$


$\mathrm{Mi}$ - value of danger (toxichess) index in accordance with danger class; $\mathrm{n}$ amount of chemical elements being considered; $\mathrm{Kc}$ - coefficient of concentration (C) of a chemical element (i); $\mathrm{Tj}$ - translocational indicator of harmfulness shown in relative units ( for soils -2 , air -3 , underground waters 4, biomass - 5); $\mathrm{m}$ - quantity of components ( $\mathrm{j}$ ) of a landscape. Indicators $\mathrm{Pj}$ and In are considered main in the estimation of the ecological-geochemical condition of an area.

The mountain territory of North Bukovina notes the diversity of landscape, ecological, geophysical, and geochemical characteristics. Existing vertical differentiation of landscapes has led to a complex set of elementary geochemical landscapes.

Our research covers mainly valley-terraced landscape complexes with a chain of rural settlements related to mountain forest meadow, sour, transeluvial-super-aquatic landscapes geochemical systems.

Ground waters on the whole for the investigated territories, $\mathrm{pH}$ - neutral and slightly acidic; hardness - soft and moderately hard; the level of salinity fresh and ultra-fresh. The nitrite content is less than $0,01 \mathrm{mg} / \mathrm{dm}^{3}$, nitrate less than $0,11 \mathrm{mg} / \mathrm{dm}^{3}$, ammonium lest than $0,08 \mathrm{mg} / \mathrm{dm}^{3}$.

The content of heavy metals in water samples has mainly the following parameters $\left(\mathrm{mg} / \mathrm{dm}^{3}\right): \mathrm{Pb} 0,001-0,028$ (the average value is 0,014$), \mathrm{Zn} 0,02-0,31$ (average 0,12 ), $\mathrm{Cu}$ ranged from 0,005 to 0,07 (with an average of 0,03 ), the values for $\mathrm{Cd}$ in water samples of all of the key areas range from 0,001-0,002 $\mathrm{mg} / \mathrm{dm}^{3}$. Dangerous levels of these trace elements in groundwater of the study area were undetected. Mostly, there is a calcium bicarbonate, calcium bicarbonate-sodium, bicarbonate-sodium-calcium, chloride-sodium water.

Soil (light brown mountain-forest, dark-brown mountain-forest, sodbrown) are predominantly acidic and slightly acidic reaction, the humus maintenance of up to 3-4\%. According to data analysis of the total content of heavy metals observed different migration ability in various elementary geochemical landscapes vertical profile. A more pronounced accumulation of all the investigated elements $(\mathrm{Pb}, \mathrm{Zn}, \mathrm{Cu}, \mathrm{Cd})$ is observed in the background brown mountain-forest soils transelluvial locations. Overall, among the heavy metals of greatest migration capacity within the study area are characterized by $\mathrm{Zn}, \mathrm{Cu}, \mathrm{Cd}$ and to a lesser $\mathrm{Pb}$ (Tanasiuk, 2014).

The soil surface $\mathrm{Pb}$ content ranges $1,5-3,7 \mathrm{mg} / \mathrm{kg}$ soil, $\mathrm{Zn}$ - from 28,1 до 71,0 . Analysis of $\mathrm{Pb}$ content showed that increased rates, characteristic to superaquatic elementary geochemical landscapes, where it accumulates. $\mathrm{Cu}$ content varies from 12,4 to $34,9 \mathrm{mg} / \mathrm{kg}$, Cd-values from 0,017 to $0,077 \mathrm{mg} / \mathrm{kg}$.

On the basis of the microelements contents data in the soils of rural geosystems of the mountain areas of Northern Bukovina, there being calculated 
concentration coefficients (tables 1), there being determined the indicators of contamination intensivity of the natural component $(\mathrm{Pj})$ and the integral integral indicator of ecological safety (In) (tables 2).

Tables 1.Coefficients of microelements concentration in soils of the rural geosystems of the mountain areas of Northern Bukovina

\begin{tabular}{cccccc}
\hline o & Code of a sample & $\mathbf{P b}$ & $\mathbf{Z n}$ & $\mathbf{C u}$ & $\mathbf{C d}$ \\
\hline 1 & Y1 & 0,14 & 1,10 & 1,08 & 1,40 \\
2 & Y2 & 0,26 & 0,73 & 0,44 & 0,54 \\
3 & Y3 & 2,08 & 1,08 & 1,00 & 1,73 \\
4 & Y4 & 1,51 & 1,06 & 1,43 & 1,57 \\
5 & P5 & 0,45 & 0,23 & 0,87 & 0,68 \\
6 & P6 & 1,71 & 0,32 & 1,11 & 0,41 \\
7 & P7 & 0,93 & 2,44 & 1,01 & 2,32 \\
8 & S8 & 1,25 & 0,60 & 0,95 & 1,85 \\
9 & S9 & 1,24 & 1,04 & 1,14 & 0,74 \\
10 & S10 & 0,93 & 0,80 & 1,94 & 1,32 \\
11 & S11 & 1,63 & 0,81 & 1,06 & 2,58 \\
12 & S12 & 0,66 & 1,51 & 0,91 & 1,25 \\
13 & S13 & 0,65 & 1,13 & 0,69 & 0,57 \\
14 & S14 & 1,00 & 0,86 & 0,70 & 0,64 \\
15 & S15 & 0,92 & 0,99 & 0,75 & 0,66 \\
16 & S16 & 0,96 & 1,22 & 0,82 & 0,68 \\
17 & minimum & 0,14 & 0,23 & 0,44 & 0,41 \\
18 & maximum & 2,08 & 2,44 & 1,94 & 2,58 \\
19 & medium & 1,02 & 0,99 & 0,99 & 1,18 \\
\hline
\end{tabular}

According to the analysis of the coefficient of concentration $(\mathrm{Kc})$ heavy metals the soil surface of the study area, it is established that the highest. $\mathrm{Kc} \mathrm{Pb}$ characteristic to super-aquatic elementary geochemical landscapes, where it accumulates. $\mathrm{Kc} \mathrm{Cu}$ varies from 0,69 (trans-eluvial) to 1,94 (super-aquatic), the value of $\mathrm{Cd}$ ranged from 0,57 (eluvial) to 2,58 (super-aquatic) elementary geochemical landscapes.

Index of the intensity of soil pollution of the territory varies from 7,4 to 25,7 . The total showings of contamination here is in the range of 1,2 to 2,7 . The environmental risk factor for $\mathrm{Pb}$ content varies from 0,05 to $0,12, \mathrm{Cd}-0,01$ to $0,07, \mathrm{Cu}-0,20-0,62$, and $\mathrm{Zn}-0,28-0,71$.

The index of saturation of soils with heavy metals varies from 0,76 to 1,52 . Their accumulation occurs mainly in super-aquatic elementary geochemical landscapes, and dispersion and background values are most characteristic eluvial and trans-eluvial. 
In general, coefficients for radial migration and migration indicators indices of heavy metals in soil profiles, it is possible to speak about its accumulation in the transitional horizons and migration from the upper humus horizons. Such radial differentiation heavy metals characteristic eluvial and super-aquatic elementary geochemical landscapes.

Tables 2. Showings of contamination intensivity of natural components $(\mathrm{Pj})$ and showings of ecological safety (In)

\begin{tabular}{cccccccc}
\hline № & $\begin{array}{c}\text { Code of a } \\
\text { sample }\end{array}$ & $\mathbf{P b}$ & $\mathbf{Z n}$ & $\mathbf{C u}$ & $\mathbf{C d}$ & $\sum \mathbf{P j}_{\mathbf{2}}$ & $\sum \mathbf{P j}_{\mathbf{2}} * \mathbf{T j}_{\mathbf{2}}$ \\
\hline 1 & Y1 & 0,56 & 4,4 & 3,24 & 5,6 & 13,8 & 27,6 \\
2 & Y2 & 1,04 & 2,92 & 1,32 & 2,16 & 7,44 & 14,88 \\
3 & Y3 & 8,32 & 4,32 & 3 & 6,92 & 22,56 & 45,12 \\
4 & Y4 & 6,04 & 4,24 & 4,29 & 6,28 & 20,85 & 41,7 \\
5 & P5 & 1,8 & 0,92 & 2,61 & 2,72 & 8,05 & 16,1 \\
6 & P6 & 6,84 & 1,28 & 3,33 & 1,64 & 13,09 & 26,18 \\
7 & P7 & 3,72 & 9,76 & 3,03 & 9,28 & 25,79 & 51,58 \\
8 & S8 & 5 & 2,4 & 2,85 & 7,4 & 17,65 & 35,3 \\
9 & S9 & 4,96 & 4,16 & 3,42 & 2,96 & 15,5 & 31 \\
10 & S10 & 3,72 & 3,2 & 5,82 & 5,28 & 18,02 & 36,04 \\
11 & S11 & 6,52 & 3,24 & 3,18 & 10,32 & 23,26 & 46,52 \\
12 & S12 & 2,64 & 6,04 & 2,73 & 5 & 16,41 & 32,82 \\
13 & S13 & 2,6 & 4,52 & 2,07 & 2,28 & 11,47 & 22,94 \\
14 & S14 & 4 & 3,44 & 2,1 & 2,56 & 12,1 & 24,2 \\
15 & S15 & 3,68 & 3,96 & 2,25 & 2,64 & 12,53 & 25,06 \\
16 & S16 & 3,84 & 4,88 & 2,46 & 2,72 & 13,9 & 27,8 \\
17 & minimum & 0,56 & 0,92 & 1,32 & 1,64 & 7,44 & 14,88 \\
18 & maximum & 8,32 & 9,76 & 5,82 & 10,32 & 25,79 & 51,58 \\
19 & medium & 4,08 & 3,98 & 2,98 & 4,73 & 15,77 & 31,55 \\
\hline
\end{tabular}

Analysis of the biomass of the study area showed a slight concentration heavy metals. The concentrations of heavy metals maintained in the following ranges $(\mathrm{mg} / \mathrm{kg})$ : $\mathrm{Pb} 0,06-0,08, \mathrm{Zn} \mathrm{9,3}$ to $26,8, \mathrm{Cu} 6,07-9,97, \mathrm{Cd} 0,01$ to 0,02 . The maximum content of $\mathrm{Zn}, \mathrm{Cu}$ and $\mathrm{Cd}$ characteristic eluvial, and $\mathrm{Pb}$ to transeluvial and super-aquatic elementary geochemical landscapes. Biogeochemical anomalies in the study area are not detected (Tanasiuk, 2013).

Rural geosystems have their own peculiarities such as landscape-ecological diversity, high dependence of geochemical characteristics on anthropogenic loading, and contamination including as a result economical activity.

Main tasks of investigation and study of rural geosystems are development and implementation of principles and methods of optimization of their geochemical qualities. It is reflected in the necessity to regulate society 
influence on the environment. So, its is crucial to develop such means of controlling on all aspect nature management which would locate as precisely as possible unfavourable situations and enable the development of nature conserving measures concerning the management of a pertaining to national economy activity in corresponding landscape complexes.

\section{Conclusions.}

Concerning the received ecological characteristics and indicator we can give an overall estimation of the ecology-geochemical situation of rural geosystems of the mountain areas of Northern Bukovina. Thus, according to ecological-geochemical indicators the investigated area belongs to a favourable one, i.e. there is no contamination. The category of contamination intensivity is moderately valid, the amount $-\mathrm{Pj}$ varies from 15 to 30 . Such results according to the evaluating scale of ecological safety of landscape contamination indicate a low level incidence and the minimal frequency of functional deviations the health of the population.

Ecological-geochemical indicators do not exceed the limiting allowable concentrations, significant geochemical contamination of rural settlements in mountain areas not detected that indicates their favourable ecological condition.

\section{Bibliography:}

Dmitruk Y. M. (2006), Ecological and geochemical analysis of soil agroecosystems / Dmitruk Y. M. - Chernivtsi: Ruta, - 328 sec.

Gutsuliak V.M. (2002), Landscape Ecology: geochemical aspect: teach. User / Gutsuliak V.M. - Chernivtsi: Ruta, - 247 sec.

Gutsuliak V.M. (1994), Geochemistry: Manual. - Chernivtsi: Ruta, - 82s.

*** (1978), Nature of Chernivtsi region / edited by K.I. Gerenchuka - Lviv: High School, 1978. - $160 \mathrm{p}$.

Tanasiuk M.V. (2013), Ecological-geochemical features of urban landscapes Putila / Collection of scientific publication. Vol. 672-673: Geography, Chernivtsi National university, Chernivtsi, Ukraine, p. 52-56.

Tanasiuk M.V. (2014), Landscape-geochemical assessment of the ecological state of the territory Selyatynskoyi depression / Collection of scientific publication. Vol. 696: Geography, Chernivtsi National university, Chernivtsi, Ukraine, p. 44-46. 
